\title{
HEALTH MONITORING IN LANDING GEARS
}

\author{
Zbigniew Skorupka, Andrzej Tywoniuk \\ Institute of Aviation \\ Krakowska Av. 110/114, 02-256 Warszawa, Poland \\ tel.:+48 228460011 ext. 657, ext. 219, fax: +48943426753 \\ e-mail: zbigniew.skorupka@ilot.edu.pl,andrzej.tywoniuk@ilot.edu.pl
}

\begin{abstract}
Every mechanical construction loses its properties in time due to the usage wear that leads to malfunctions and, in the end, to failure. Widely used method of failure time prediction base on extended laboratory tests where a device is tested against fatigue and wear. This method is well established but is expensive, time-consuming, and costly. Another way of failure prediction is to calculate it using advanced algorithms what is faster and cheaper but less accurate than actual tests. Furthermore, both methods are not optimal due to the principle of operation based on simplified assumptions. In such cases, it is common to make the lifespan of the safety wise devices for example landing gears much less than real in case of fatal failure not covered by the predictions. This can lead to much higher price and maintenance costs of the landing gear. Nowadays the worldwide trend is to monitor the behaviour of the devices in real time and predict failure using actual state. There are several methods of health monitoring, most of them including sensors, acquisition systems and computer software for analysis.

In this article, authors describe possible landing gears health monitoring methods based on authors' laboratory experience in sensor appliance and test data analysis. The authors also present their idea of adding health monitoring to existing landing gears where no dedicated infrastructure was initially designed.
\end{abstract}

Keywords: health-monitoring, landing gear, load measurement, pressure measurement, strain gauges

\section{Introduction}

Every machine loses its properties in time. It can be manifested by degradation in movement precision, by decreasing the maximum operating parameters or construction failure. The failure can be a result of wear (e.g. plain bearings having more and more movement resistance over time) or material failure (e.g. cracks) mostly due to the fatigue. In addition, the exceeding level of critical loads results in machine failure or even its destruction. In order to prevent failures and extend the lifetime of the constructions some precautionary measures are made.

Most common is to design the mechanical device in the manner that it never exceeds permissible operational parameters. This method is effective but comes with the over scaled design, which costs much more than optimized one would. The approach also does not prevent the natural wear of the machines pushing back in time point of degradation not always as far as expected.

Second method is to foreseen (by statistical tools [3]) occurrence of the highest loads and optimises the design to be able to cope with them. The approach is only valid when maximum loads are rare and their occurrence cannot harm the machine (e.g. big force acting on the machine from time to time for a brief period). Statistical method can be mostly applied to the known designs, the second version of the previously made machine, or, when laboratory tests can be performed in order to collect statistics. The purely theoretical approach is also permissible but with caution and limited accuracy. Due to the need for statistical data, this optimization approach is quite expensive therefore; it can be applied to the mass-produced machines or can be adapted to the design sharing the similarities with other widely used. As for the previously described method, the lifespan of the product or failure prevention is purely theatrical so the usage threshold must be put on the safe side of the operation. That leads to the shortened operation time due to the safety concerns and by that is not optimal from both operation and economical points of view. 
The most efficient method is to gather data usage in real time and customize the operation of the machine accordingly. The method is being applied in almost every new design where the safety of the operation and lifespan optimization is required. This type of health monitoring is based on the set of sensors recording operational data, which is analysed in order to estimate current state of the machine [2]. The health monitoring can be performed in real-time (for crucial safety equipment or for the machines operating in long periods without stopping) or between operations. Health monitoring can also be useful in order to optimize lifespan of the design by the confrontation of calculated and collected operation data in order to lengthen or shorten construction lifespan. Data collected is also invaluable in failure prediction.

Heath monitoring in both described versions is being widely adopted in aviation for both safety assurance and equipment lifespan extension points of view.

There is a number of health monitoring methods to be used in landing gears. For new and prototype designs, the modern choice will be the usage of the fibre optics [7] but can cause need of too deep modernization in existing landing gear designs. In this case health monitoring has to be added without changing whole construction what is not recommended due to the economic and operational reasons - there has to be made the new design, new parts has to be made, and whole certification process has to be repeated. The proposed methods of the landing gears health monitoring are described in the following parts of this article.

\section{Health monitoring methods in existing landing gears}

For existing design, there are several methods of health monitoring:

1. Force measurement [6] in the landing gear mounting nodes by strain gauge based devices (Fig. 1.). This type of measurement can be used in almost all of the landing gear test configurations. Mounting node method can be used on an aircraft for real-time force estimation; it can help to perform health monitoring (forces, fatigue, strength). The method bases on direct force measurement in fuselage mounting nodes via specially designed mounting pins or by strain gauge equipped mounting interfaces on the fuselage side. Pin force measurement can be performed in almost every landing gear node using it for example e.g. in torque links, shock absorber or cantilever nodes. The main difficulty of such measurement is well to define the state of the loads in the pin in order to achieve satisfying accuracy. Naturally, even not-well-estimated load state can be useful when reference is made. In either case, laboratory tests are necessary in order to define correct load references for each node.

2. Pressure measurement. Every shock absorber has to be pressurised in order to operate [1]. The correct level of pressures are identified and evaluated during the design stage and later confirmed and/or optimized in the laboratory tests of a landing gear [5]. There are three most important pressure values in shock absorbers: inflate pressure, static load/deflection pressure, and highest safe defined load pressure (acquired from the permissible load test). These three pressures can be used in simple health monitoring for shock absorber state.

First - the inflate pressure - is to be used only when aircraft is not touching the ground (being lifted on jacks or being in the air with landing gear fully extended) and can indicate the primary condition of the landing gear either during maintenance works or during landing. When inflate pressure is indicated being wrong on maintenance there can be a leak or just wrong inflation. When inflate pressure is wrong during landing, it is a signal for the pilot to land with lower than recommended vertical speed due to the possibility of higher deflection (too low pressure) or exceeding permissible loads (too high pressure). It is necessary to remember that in general, shock absorber inflate pressure acts on both static load and safe load pressure as well.

Second - the static load/deflection pressure - is present when aircraft is on the ground standing loaded as recommended in technical specification. Variation of that pressure can be the result of different from expected inflation pressure, not correct shock absorber operation, or 
overweighting of the aircraft. In all of the cases, it can lead to failure of the landing gear during landing.

Third and most important from the reliability of landing gear point of view is the highest safe defined load pressure, which value is the result of the permissible load test. This pressure is the highest pressure, which can occur in the correct operation of the landing gear. Exceeding it can lead to higher wear of the landing gear (when the transgression is lower than $150 \%$ ) or even to permanent damage of the landing gear when pressure is above 1.5 safety factor.

Pressures can be monitored in the described three points only (recording single values) or continuously (in whole operation time) for better estimation of the current state of the landing gear. In addition, it is necessary to remember that pressures are directly connected to the forces acting in the shock absorber.

One more pressure that can be useful in the landing gear health monitoring is the pressure in the wheel. Its monitoring can be helpful in order to estimate actual condition of the wheel and is directly connected to the shock absorbers operation (properly inflated tyre acts as shock absorber auxiliary component).


Fig. 1. Mounting node force measurement devicelaboratory version (example) [source ILot]

Fig. 2. Strain gauges mounted on the landing gear (example) [source ILot]

3. Strain gauge based strain and stress measurement (Fig. 2.). This type of health monitoring can be applied to the whole landing gear and can be useful of direct monitoring most loaded nodes in the landing gear itself. Nowadays strain gauges are miniaturized as much as can be used as real-time direct state monitoring system in almost any design. Mounting of the strain gauges can be done even on working constructions where are no areas specially designed for that purpose. Strain gauges measurement provides the full set of data that can be helpful in order to obtain history of the landing gear usage or just provide the information of the exceeding the warning levels. Proper evaluation of the data can be useful in operational condition lifetime extensions of the components - what is mostly done in laboratories under the regulatory supervision. It can also provide (after correct calculations) knowledge of the load levels in each measured node.

Strain gauge based health monitoring has its downsides such as proper installation, proper protection of installed strain gauges, number of electric wires, which have to be routed on the landing gear, proper anti-electrical interference protection from both internal and external 
sources, and proper (sometimes extensive) number of signal amplifiers and conditioners. That makes described method difficult to use but the outcome can be rewarding.



Fig. 3. Schematic of described modes of measurement in Landing Gear health monitoring [source ILot]

\section{Results}

All of the described methods had been laboratory tested on existing landing gears during optimisation and qualification tests. Tests were performed using 10T drop test machine [5] as standard free fall dynamic drop tests. Basic technical data of the test stand and measurement equipment used are shown in Tab. 1.

Tab. 1. 10T drop test stand technical data

\begin{tabular}{|c|l|l|}
\hline $\mathbf{N}^{\mathbf{0}}$ & \multicolumn{1}{|c|}{ Name of parameter } & \multicolumn{1}{c|}{ Value } \\
\hline 1. & Max. weight of tested object including mounting parts & $10 \mathrm{~T}$ \\
\hline 2. & Max. forces during the tests: & $392 \mathrm{kN}$ \\
\hline & Vertical force & $196 \mathrm{kN}$ \\
\hline & Horizontal force & $157 \mathrm{kN}$ \\
\hline & Side force & $400 \mathrm{~km} / \mathrm{h}(111 \mathrm{~m} / \mathrm{s})$ \\
\hline 4. & Max. wheel spinning velocity & $28.8 \mathrm{~km} / \mathrm{h}(8 \mathrm{~m} / \mathrm{s})$ \\
\hline 5. & Max. sink speed &
\end{tabular}

Presented graphs show the variety of data, which can be acquired when described health monitoring measurement methods are engaged. All collected data can be useful in different approaches to the health monitoring system and can be used together or separately. The data can also be used not only for the monitoring of the current state of landing gear system via load and strain analysis but can be translated to the fuselage for example by calculating force from strain (Fig. 6 and 7) and comparing it to the directly measured forces or pressures (Fig. 5 and 8). Loads comparison from different measurements can be also treated as a safe-fail system for health monitoring self-diagnostic using the principle that the landing loads measured with different means should give similar results in one measurement object [4]. Presented results are also the proof-ofconcept that landing gear designs not dedicated to use of the health monitoring can be successfully equipped with it. 




Fig. 4. Free fall dynamic drop test machine example. Note the ground plate below the landing gear [source ILot]

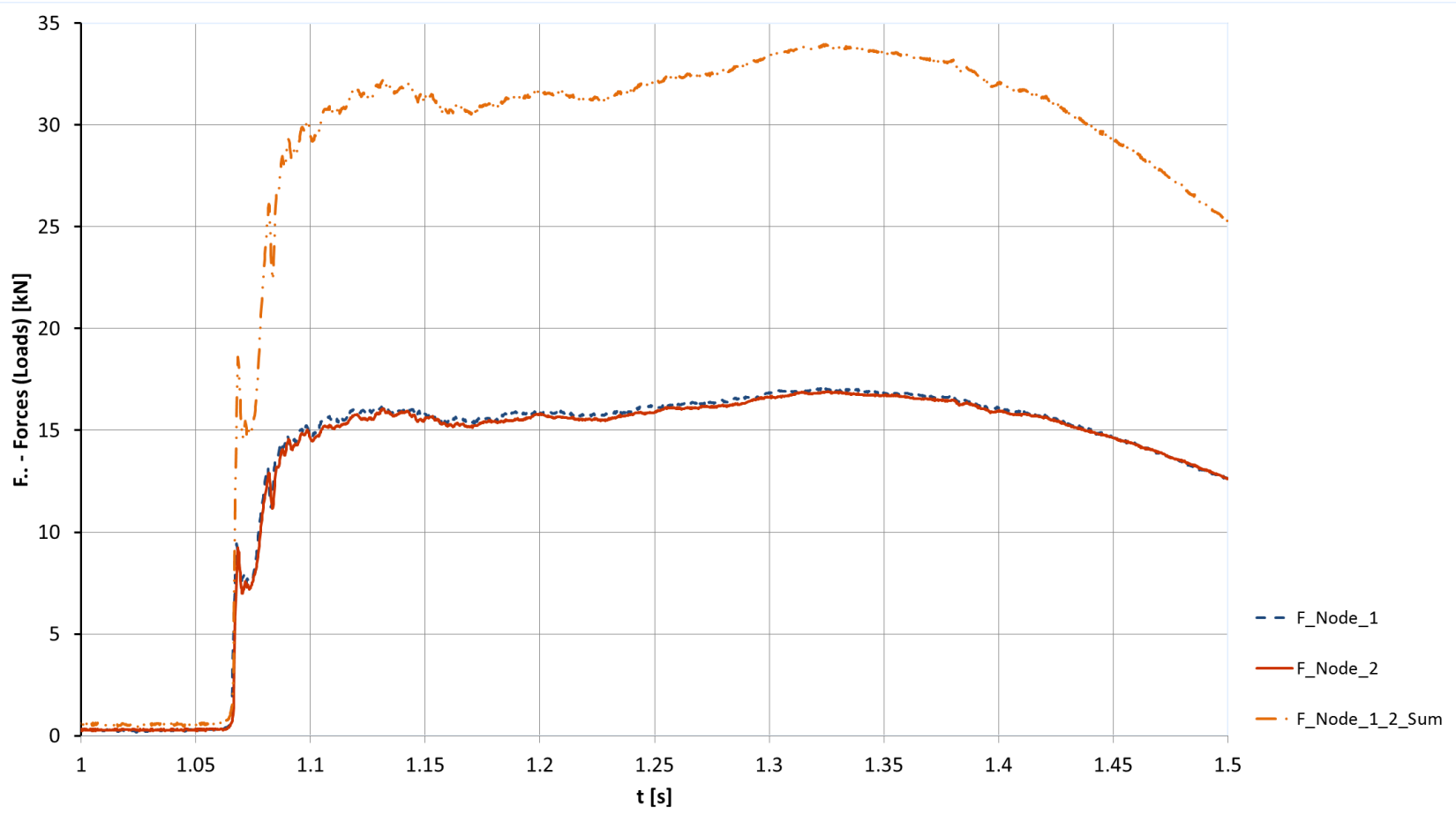

Fig. 5. Dynamic Drop Test results of node load measurement (where: $F \_$Node_1 and F_Node_2-loads/forces in mounting nodes, F_Node_1_2_Sum-full load/force acting on fuselage) - example [source ILot] 


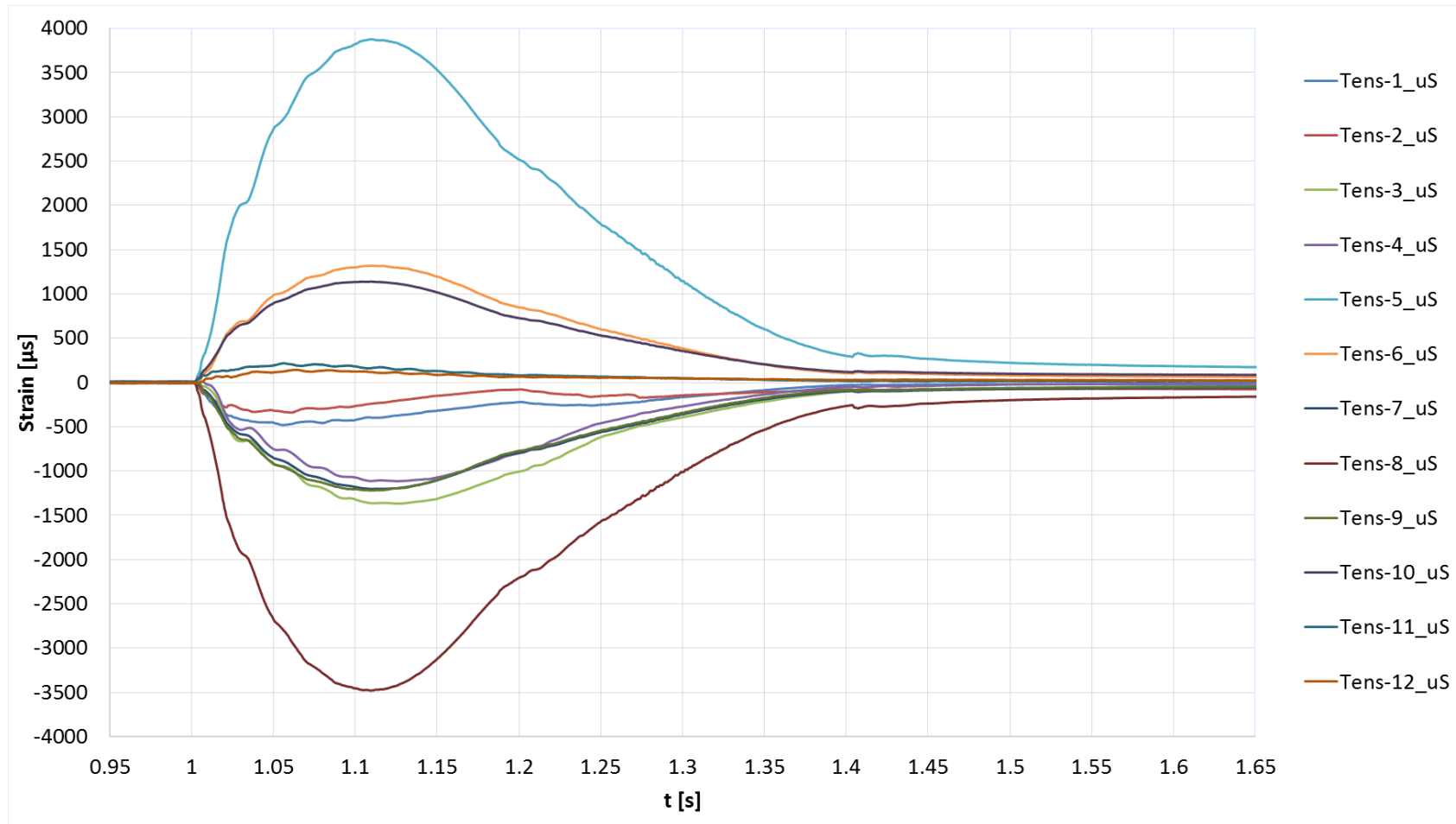

Fig. 6. Dynamic Drop Test results of strain in various areas of the landing gear (where: Tens- $X \_u S$ is strain gauge number X) - example [source ILot]

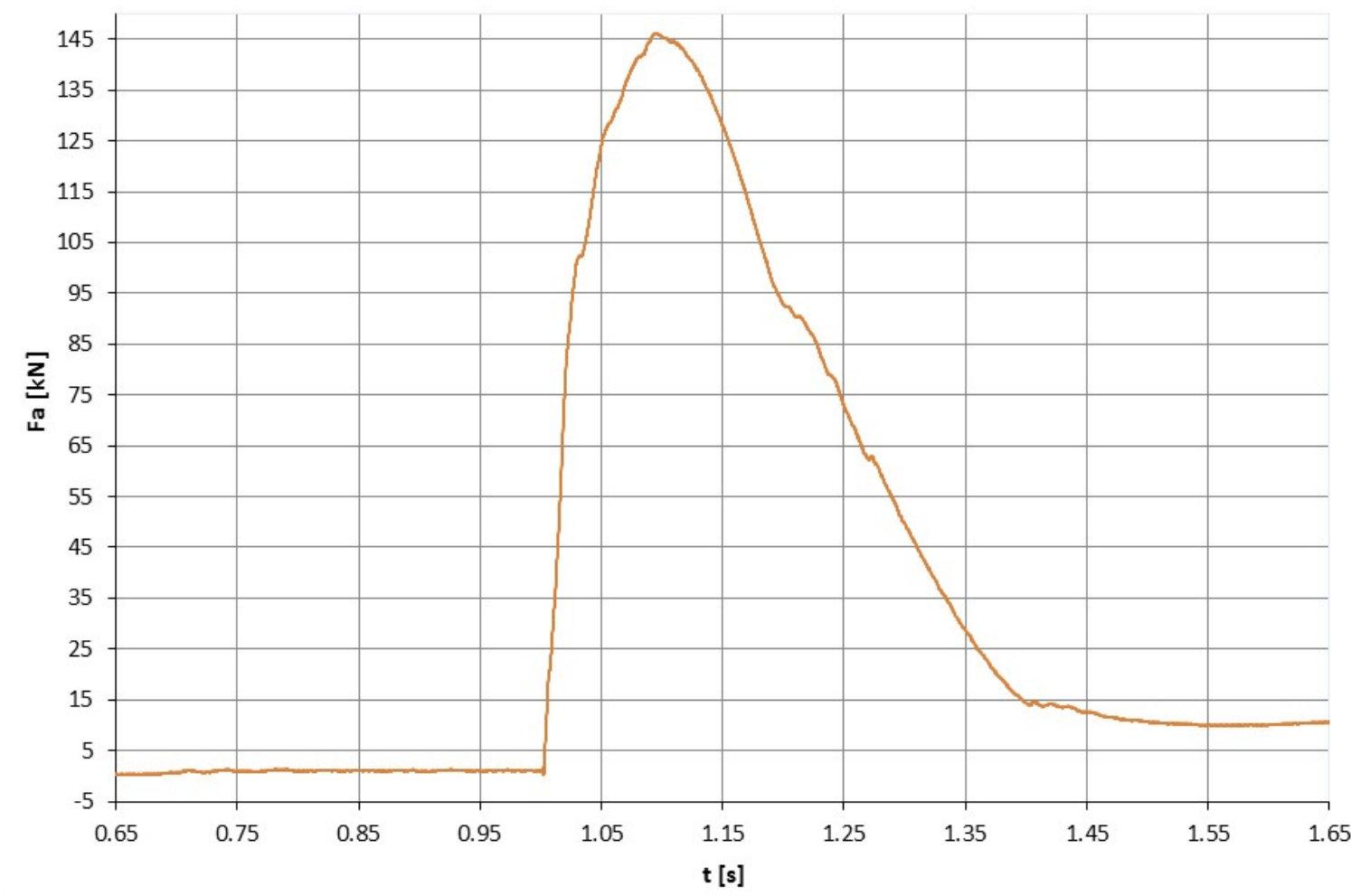

Fig. 7. Dynamic Drop Test results of force in one of the strain gauge areas calculated out of strain gange measurement - example [source ILot] 


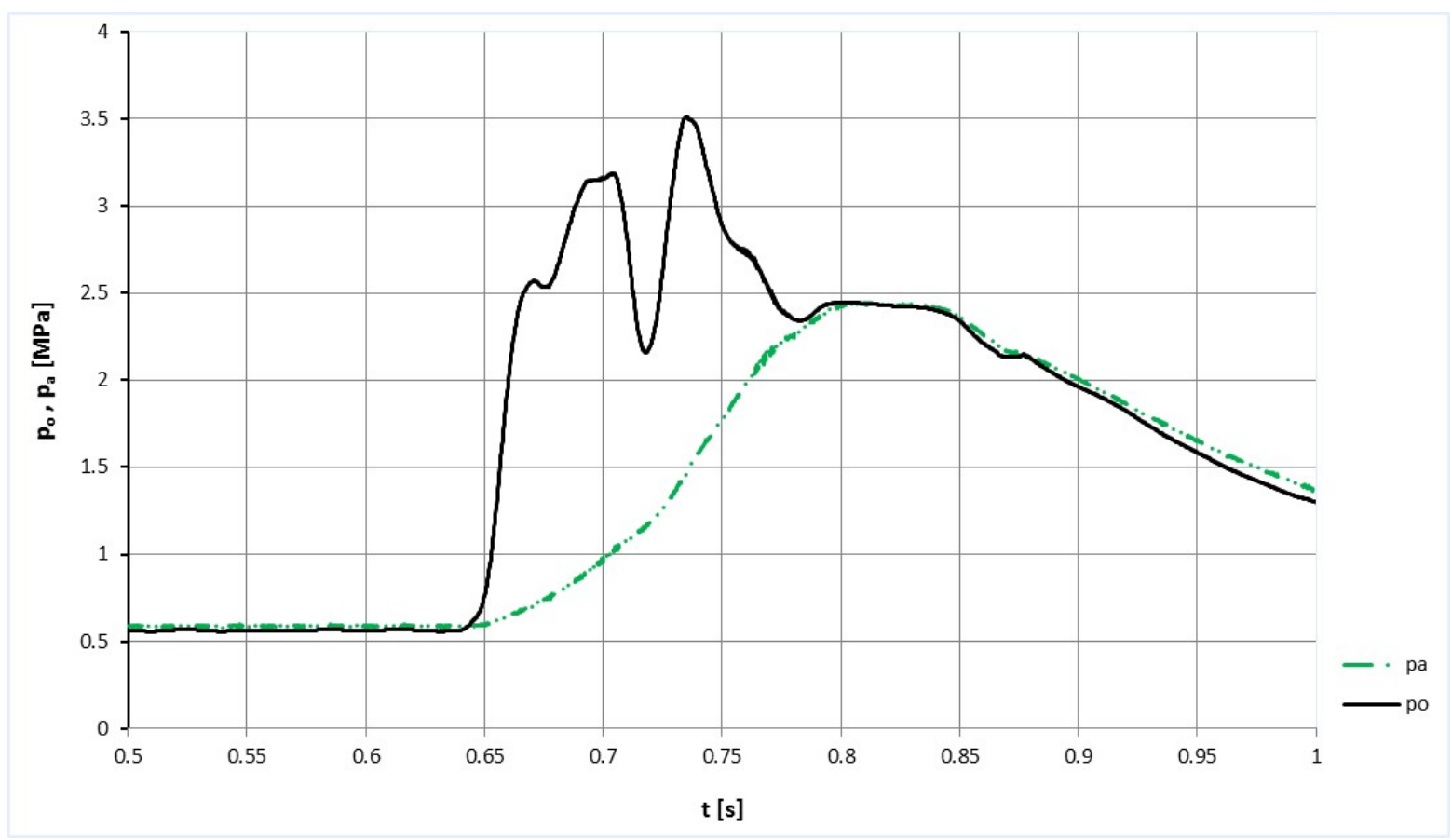

Fig. 8. Dynamic Drop Test results of pressures (where $p_{a}-$ gas pressure, $p_{o}-$ hydraulic fluid pressure) - example [source ILot]

\section{Summary}

Health monitoring in landing gears as well as in other components of the aircraft delivers crucial operational data for the safety of the aircraft (passengers, cargo) $[8,9]$. The data itself can be useful in many applications, cannot in real aircraft but also in order to obtain data for the laboratory evaluation of the design required by the aviation regulation. While fibre optics approach is currently used in newer designs, the described methods can be used in existing designs with little revisions needed. Described approach base on commonly used laboratory grade measurement methods therefore the health monitoring system can be also used as laboratory system widely recognized by the authorities. In this case, the data can be both the proof of regulations compliance and the necessary operational data collection for the final system. In the laboratory stage of tests, it is possible to estimate the warning levels for later operation of the system. That approach is also costefficient due to the duality of the process.

All of the tests and analysis described in this article were performed in the Landing Gear Laboratory of Institute of Aviation in Warsaw (one of the few independent laboratories performing Landing Gear tests, optimization and scientific research in EU), Poland where the author works on daily basis.

\section{References}

[1] Kowalski, W., et al., State of the art in landing gear shock absorbers, Transactions of the Institute of Aviation, $\mathrm{N}^{\mathrm{o}}$ 181, 2005.

[2] Petrone, G, Bruno, M. et al., An Innovative Health Monitoring System for Aircraft Landing Gears, 8th European Workshop On Structural Health Monitoring (EWSHM 2016), Spain, Bilbao 2016.

[3] Philips, P. A., Health Monitoring of Electrical Actuators for Landing Gears, The School of Mechanical, Aerospace and Civil Engineering, Phd Thesis, Manchester 2012.

[4] Skorupka, Z., Laboratory Investigations on Landing Gear Ground Reactions (Load) Measurement, Journal of KONES, Vol. 24, No. 2, Warsaw 2017. 
[5] Skorupka, Z.. Paprzycki, I., Laboratoryjne badania podwozi lotniczych, Transport Przemysłowy i Maszyny Robocze, Wrocław 2014.

[6] Sobieszek, A., Paprzycki, I., Tywoniuk, A., Landing Gear Dynamic Tests With Strain Gages, Journal of KONES Powertrain and Transport, Vol. 22, No. 3, 2015.

[7] Yang, D., Wang, J., et al., Fatigue crack monitoring using plastic optical fibre sensor, 2nd International Conference on Structural Integrity, ICSI 2017, Funchal, Madeira, Portugal 2017.

[8] Certification Specifications for Large Rotorcraft, CS-29, European Aviation Safety Agency (EASA).

[9] Normal, Utility, Aerobatic and Commuter Aeroplanes, CS-23, European Aviation Safety Agency (EASA).

Manuscript received 07 January 2019; approved for printing 21 March 2019 